\title{
PATOLOGIA DOS ANEXOS OCULARES
}

\author{
OCULAR ADNEXAL PATHOLOGY
}

Antonio A.V.Cruz ${ }^{1}$, Fernando Chahud ${ }^{2}$, Fernando C. Guimarães ${ }^{2}$

Docente'; Pós-graduandos² do Departamento de Oftalmologia e Otorrinolaringologia da Faculdade de Medicina de Ribeirão Preto da Universidade de São Paulo.

CoRRESPONDÊNCIA: Antonio A.V. Cruz - Departamento de Oftalmologia e Otorrinolaringologia da Faculdade de Medicina de Ribeirão Preto - Hospital das Clínicas - Campus Universitário - CEP: 14048-900 - Ribeirão Preto-SP - E-mail: aavecruz@fmrp.usp.br

CRUZ AAV; CHAHUD F \& GUIMARÃES FC. Patologia dos anexos oculares. Medicina, Ribeirão Preto, 30: 36-51, jan./mar. 1997.

RESUMO: Os principais temas da patologia dos anexos oculares foram revistos, com ênfase nas patologias que pertencem ao campo de atuação da oculoplástica.

UNITERMOS: Oculoplástica. Anexos Oculares. Patologia.

Os anexos oculares constituem um grupo complexo de estruturas, que estão relacionadas ao olho, mas não fazem parte do globo propriamente dito. Os anexos são formados por conjuntiva, pálpebras, órbita (paredes e conteúdo) e vias lacrimais. Devido a grande diversidade das estruturas supramencionadas, nem todas as patologias anexiais são tratadas por um único especialista. Assim, as patologias conjuntivais, geralmente, são encaminhadas a especialistas em doença ocular externa, e os distúrbios rotacionais oculares, aos estrabólogos.

A maioria dos problemas anexiais, ou seja, os relacionados às pálpebras, vias lacrimais e órbita, formam o campo de atuação de uma especialidade oftalmológica, relativamente moderna e de crescente importância, chamada plástica ocular ou oculoplástica. Os principais tema da patologia oculoplástica são:

\section{PÁLPEBRAS}

1.1 - Transtornos da dinâmica palpebral
1.1.1 - Blefaroptoses
1.1.2 - Retrações
1.1.3 - Lagoftalmo
1.1.4 - Blefaroespasmo

1.2 - Anomalias marginais posicionais

$$
\text { 1.2.1 - Ectrópios }
$$

1.2.2 - Entrópios

1.3 - Anomalias marginais ciliares

1.3.1 - Triquíase

1.3.2 - Distiquíase

1.3.3 - Ptose ciliar

1.4 - Infecções

1.5 - Neoplasias

\section{2. ÓRBITAS}

2.1 - Síndromes Inflamatórias Agudas

2.1.1 - Celulites

2.1.2 - Síndromes Inflamatórias Idiopáticas (pseudotumores)

\section{2 - Doenças Linfoproliferativas}

2.2.1 - Hiperplasias Linfóides reacionais

2.2.2 - Linfomas

2.3 - Orbitopatia Distireoidiana

2.4 - Fraturas

2.5- Neoplasias Não-linfóides 


\section{VIAS LACRIMAIS}

\section{1 - Obstruções}

\section{2 - Inflamações: Dacriocistites}

\section{PÁLPEBRAS}

\section{1 - Transtornos da dinâmica palpebral}

A dinâmica da pálpebra superior é mais importante do que a da inferior, em virtude de seu papel fundamental na proteção e umedecimento da superfície ocular ${ }^{1,2}$.

As estruturas que condicionam a elevação da pálpebra superior são os músculos elevador palpebral, estriado e inervado pelo III nervo, e o de Müller, liso e inervado pelo Sistema Nervoso Simpático ${ }^{3 / 7}$ (Figura 1).
A retração da pálpebra inferior é exercida pela fáscia cápsulopalpebral (expansão fibrosa que se origina do ligamento de Lockoowd, funde-se com o septo, e vai até a borda inferior do tarso), e pelo músculo tarsal inferior, liso e também inervado pelo Sistema Nervoso Simpático. A fáscia cápsulopalpebral e o músculo tarsal inferior são freqüentemente referidos, de maneira conjunta, como retratores da pálpebra inferior $^{8}$ (Figura 2).

O músculo orbicular, inervado pelo facial, atua tanto na pálpebra superior como na inferior, promovendo a oclusão da fenda palpebral nos movimentos de piscar e no fechamento voluntário das pálpebras. Finalmente, o músculo frontal tem uma pequena ação de elevação da pálpebra superior.

A fenda palpebral, isto é, o espaço delineado pelas duas pálpebras, no estado de vigília, é o re-

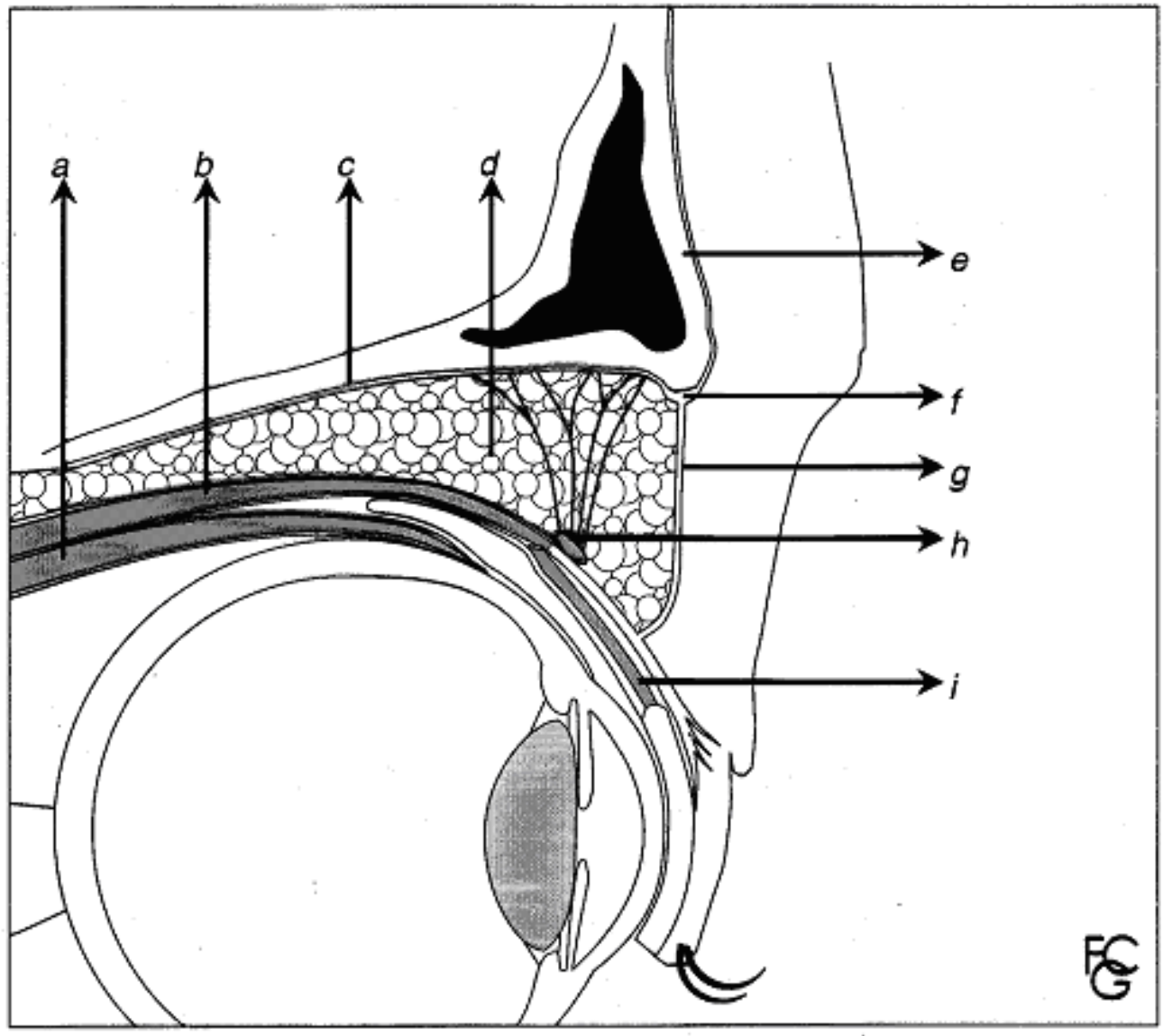

Figura 1 - Corte sagital do olho e pálpebra superior: a) músculo reto superior, b) músculo elevador palpebral, c) periórbita, d) gordura orbital, e) seio frontal, f) arcus marginalis, g) septo orbital, h) ligamento de Whitnall, i) músculo de Müller. 
sultado do equilíbrio desses elementos. Dessa maneira, qualquer anomalia na função das estruturas relacionadas à dinâmica palpebral induz, além da perda de movimento, modificação na altura da fenda palpebral. superior (Midpupil-to-upper-eyelid distance). Frueh, em 106 sujeitos normais, com idades abaixo de 65 anos, obteve o valor médio de $3.5( \pm 0.9) \mathrm{mm}$ para a medida do centro pupilar à margem palpebral superior ${ }^{10}$. Baseados nesses dados, Small et al. conceituaram ptose da

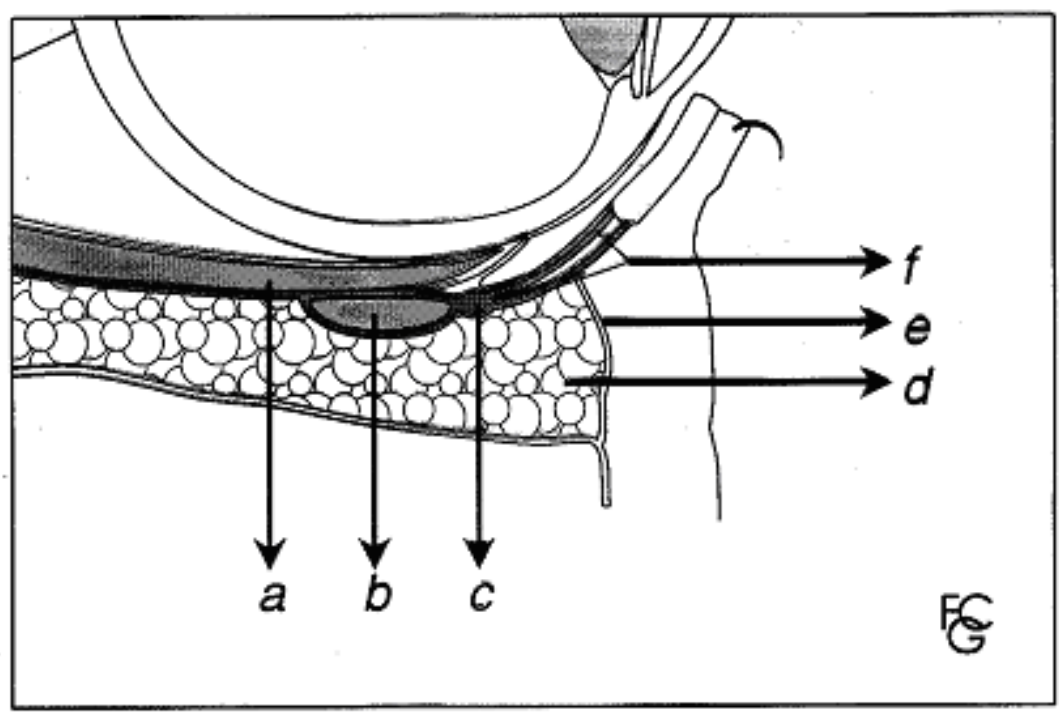

Figura 2 - Corte sagital do olho e pálpebra inferior: a) músculo reto inferior, b) músculo oblíquo inferior, c) ligamento de Lockwood, d) gordura orbital, e) septo orbital, f) retratores palpebrais (fáscia capsulopalpebral + músculo tarsal inferior).

\subsection{1 - Blefaroptoses}

Por definição, blefaroptose, ou ptose palpebral, designa a condição caracterizada pelo posicionamento anormalmente baixo da margem palpebral superior.

Modernamente, a ptose tem sido quantificada em relação ao eixo visual (eixo teórico que une a fovéola ao objeto de (ixação) ${ }^{9}$. A localização do eixo visual na córnea é possível graças à formação das imagens de primeira ordem, de Purkinje. Assim, ao se fixar um pequeno foco de luz, é fácil notar o reflexo desse foco na córnea (esse reflexo é uma imagem direta e especular da fonte luminosa, formada, principalmente, pela superfície anterior da córnea). A medida da distância dessa imagem à margem da pálpebra superior foi denominada de MRD (do inglês, Margin Reflex Distance) (Figura 3). Como a posição do reflexo luminoso é praticamente coincidente com o centro pupilar, a medida da MRDé, clinicamente, equivalente à medida do centro pupilar à margem palpebral seguinte maneira: existe ptose sempre que a MRD for menor que $2 \mathbf{~ m m}^{11}$.

É preciso notar que a medida da MRD é um critério absoluto, e não elimina o problema da assimetria interocular do posicionamento palpebral. Com efeito, se, em termos absolutos, existe uma variância da posição palpebral, há de se admitir que, mesmo em pessoas normais, é plausível uma variação interocular desse posicionamento. Assim, pode-se ter uma MRD, em um olho de $4.5 \mathrm{~mm}$ e, em outro, de $2.5 \mathrm{~mm}$. Os dados de Small et al. indicam que assimetrias de $\mathrm{MRD} \geq 2 \mathrm{~mm}$ não são normais, mesmo quando ambas as pálpebras estão $2 \mathrm{~mm}$ ou mais acima do centro pupi$\operatorname{lar}^{11}$. No entanto, isso não significa que a pálpebra mais baixa seja a patológica, pois a outra pode estar mais alta por retração palpebral. Na prática, muitas vezes, essas dúvidas só são dirimidas com a semiologia complementar.

O estudo semiótico das blefaroptoses compreende algumas etapas básicas do exame oftalmológico (medida da acuidade visual, refratometria, análise dos reflexos pupilares, biomicroscopia, fundoscopia) e

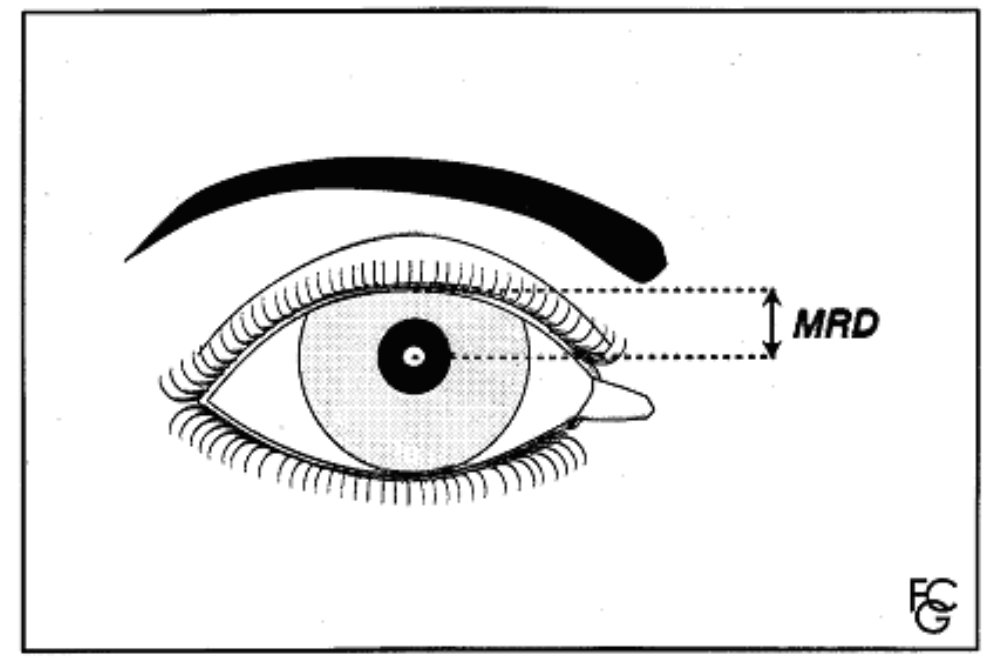

Figura 3 - Processo de medida da posição da pálpebra superior. Distância entre o reflexo corneano provocado pela fixação de uma luz puntiforme e a margem palpebral superior (MRD). 
avaliações específicas tais como: medida da função do elevador, avaliação do fenômeno de Bell e da força do músculo orbicular, e exame do sulco palpebral superior.

A medida da função do elevador palpebral é a pedra angular para o planejamento cirúrgico das blefaroptoses. Ela é feita, indiretamente, ao se quantificar a amplitude do sacádico palpebral, resultante da mudança de fixação ocular de infraversão para supraversão máxima. Operacionalmente, é importante que a posição do supercílio seja mantida em sua posição anatômica, com o polegar do examinador, enquanto se mede, com uma régua milimetrada, o deslocamento palpebral, quando os olhos se movem da posição de infraversão para a de supraversão máxima $^{12}$ (Figura 4).

Em indivíduos normais, a ação média do elevador é de 15.3 ( \pm 1.6 ) $\mathrm{mm}$, e os valores extremos situam-se entre 12 e $20 \mathrm{~mm}^{10}$. Em casos de ptose, dependendo do mecanismo etiológico, a função do elevador pode ser ausente ou praticamente normal.

As ptoses têm sido classificadas, modernamente, segundo o mecanismo etiopatogênico, em quatro categorias: miogênicas, neurogênicas, aponeuróticas e mecânicas ${ }^{13}$. Evidentemente, algumas dessas categorias permitem subdivisões clínicas, e alguns tipos de ptoses são mistos, ou seja, mais de um mecanismo atua na gênese do abaixamento da margem palpebral superior.

\section{Classificação das Ptoses}

- Miogênicas

Isoladas (congênitas)

Associadas

a - Estrabismo

b - Blefarofimose

c - Miopatias e doenças da junção neuromuscular (mitocondriopatias, outras distrofias musculares e Miastenia Grave)

- Neurogênicas

Paralisia do III nervo

Síndrome de Claude-Bernard-Horner Ptoses sincinéticas

a - Síndrome de Marcus-Gunn

b - Regeneração e inervação aberrante do III nervo

- Mecânicas

- Aponeuróticas
O detalhamento das características clínicas dos subtipos de ptose foge ao escopo desse trabalho. Vale ressaltar que a denominação "ptose congênita" refere-se ao tipo miogênico isolado. Nesses casos, há uma distrofia isolada, de magnitude variável, não evolutiva e congênita, do elevador palpebral ${ }^{14 / 17}$. Outro grupo importante é o das ptoses aponeuróticas. Estas ocorrem devido a um defeito na inserção do elevador. $\mathrm{O}$ músculo propriamente dito é normal, de modo que a função do elevador é sempre boa ${ }^{18 / 21}$. Tipicamente,
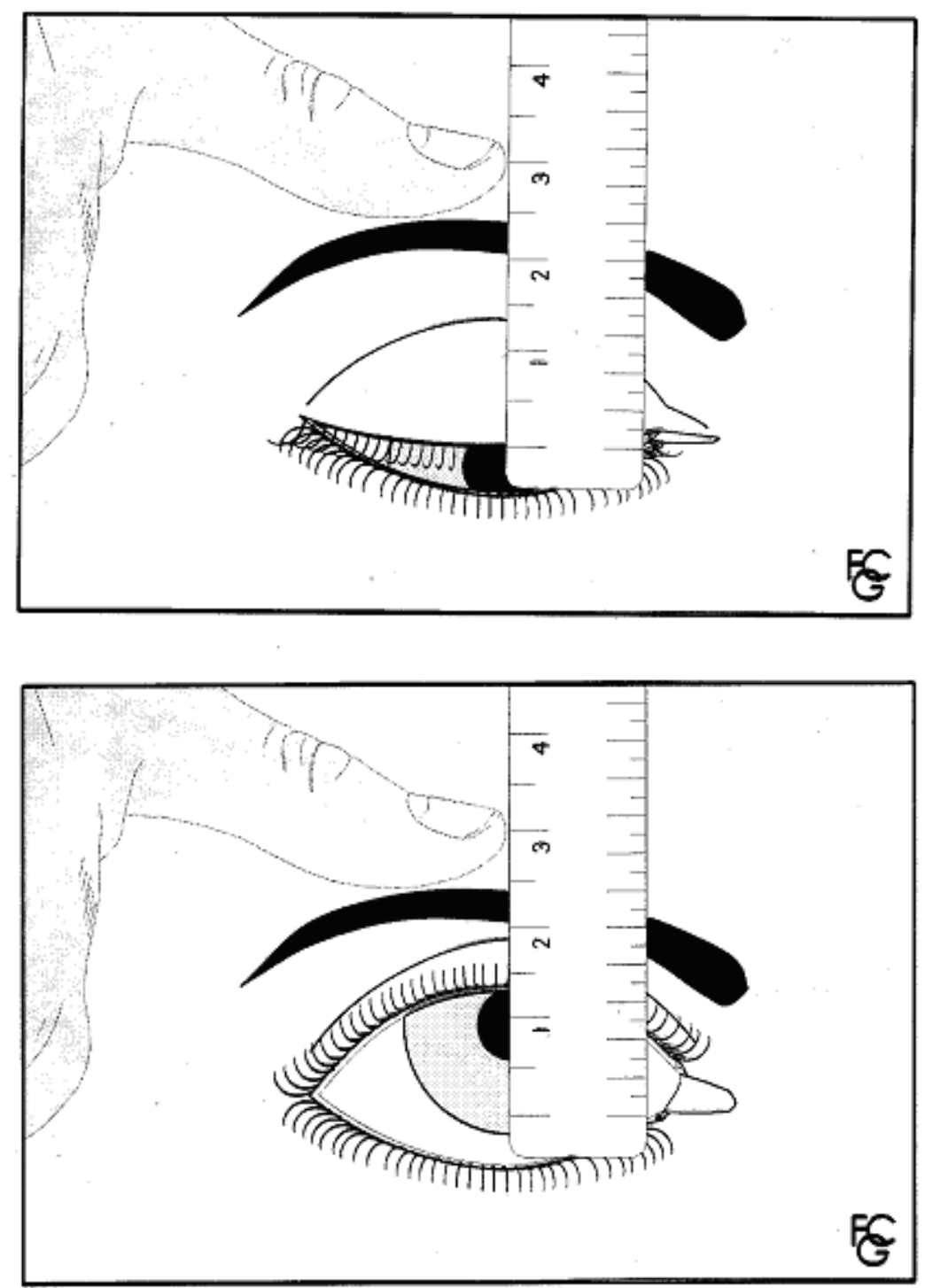

Figura 4 - Medida da função do músculo elevador palpebral: acima - com o paciente olhando para baixo, o polegar do examinador mantém o músculo frontal em posição, enquanto uma régua milimetrada é posicionada à frente da margem palpebral superior; abaixo - com o examinador mantendo o frontal em posição, o paciente olha para cima. A excursão palpebral, medida em milímetros, é tomada como a função do elevador. 
esse tipo de ptose aparece em pacientes idosos e após trauma. As ptoses miopáticas traduzem o envolvimento do elevador palpebral em processos distróficos musculares sistêmicos. Quase sempre, há déficit rotacional ocular e diminuição da ação do orbicular. Esses fatores complicam a correção desses casos, que exigem cirurgias especiais.

\subsection{2 - Retrações}

Ao contrário das blefaroptoses, condição relacionada unicamente à posição da pálpebra superior, as retrações palpebrais podem ser inferiores ou superiores.

O referencial usado para o diagnóstico quantitativo das retrações superiores é o mesmo usado nas blefaroptoses, isto é, a retração é definida a partir da medida da MRD.

A retração superior é definida como qualquer posição palpebral, cuja MRD seja maior que $5 \mathrm{~mm}^{10}$. $\mathrm{Na}$ ausência de ptose, variabilidades posicionais interoculares, maiores que $1 \mathrm{~mm}$, também são indicativas de retração palpebral.

Em relação à palpebra inferior, os valores normativos são menos caracterizados. Em vários estudos, o referencial adotado foi o limbo inferior. Assim, segundo Frueh, a posição normal da pálpebra inferior não permite o scleral show pois é tangente ao limbo ${ }^{10}$. Em outro trabalho, Shore obteve resultados diferentes. Com efeito, foram encontradas pálpebras inferiores a mais de $1 \mathrm{~mm}$ abaixo do limbo, em todas as faixas etárias estudadas ( 15 a 89 anos), principalmente, após os 50 anos de idade ${ }^{22}$.

Os nossos dados também mostram que scleral show não implica, necessariamente, em anormalidade, pois, num estudo-controle com pessoas sem pato- logia órbitopalpebral, 95\% das MRDs inferiores estavam entre 4,9 e $7.4 \mathrm{~mm}$ (média $=6.17 \mathrm{~mm}$ ). $O$ critério relativo também é importante, porque, similarmente ao que ocorre com a MRD superior, os valores dos dois olhos são bem correlacionados, e a maioria das diferenças interoculares é de 0 a $1 \mathrm{~mm}$.

Tanto as retrações superiores como as inferiores podem ser divididas em dois grandes grupos, que têm características semiológicas distintas: as retrações inervacionais e as cicatriciais ou restritivas.

Nas retrações inervacionais superiores, a margem palpebral está alta, porque o elevador palpebral e/ou músculo de Müller estão hiperativos. O termo hiperativo refere-se ao aumento da capacidade contrátil muscular. Esse aumento, que pode ser tônico ou espástico, em geral, é compatível com uma dinâmica palpebral razoavelmente preservada.

As retrações inervacionais inferiores ocorrem por estimulação simpática do músculo tarsal inferior.

As retrações cicatriciais superiores ou inferiores são caracterizadas pela presença de uma estrutura passiva que mantém a margem palpebral alta. Sempre há importante restrição da dinâmica palpebral.

\subsection{3 - Lagoftalmo}

O termo lagoftalmo refere-se à incapacidade do orbicular em ocluir da fenda palpebral ${ }^{1}$ (Figura 5). Sempre há déficit na dinâmica da pálpebra superior, que pode ser de origem neural ou cicatricial.

A deficiência neural é causada pelas paralisias e paresias do VII nervo. O lagoftalmo paralítico isolado, isto é, com comprometimento apenas do orbicular, é um sinal comum na Hanseníase.

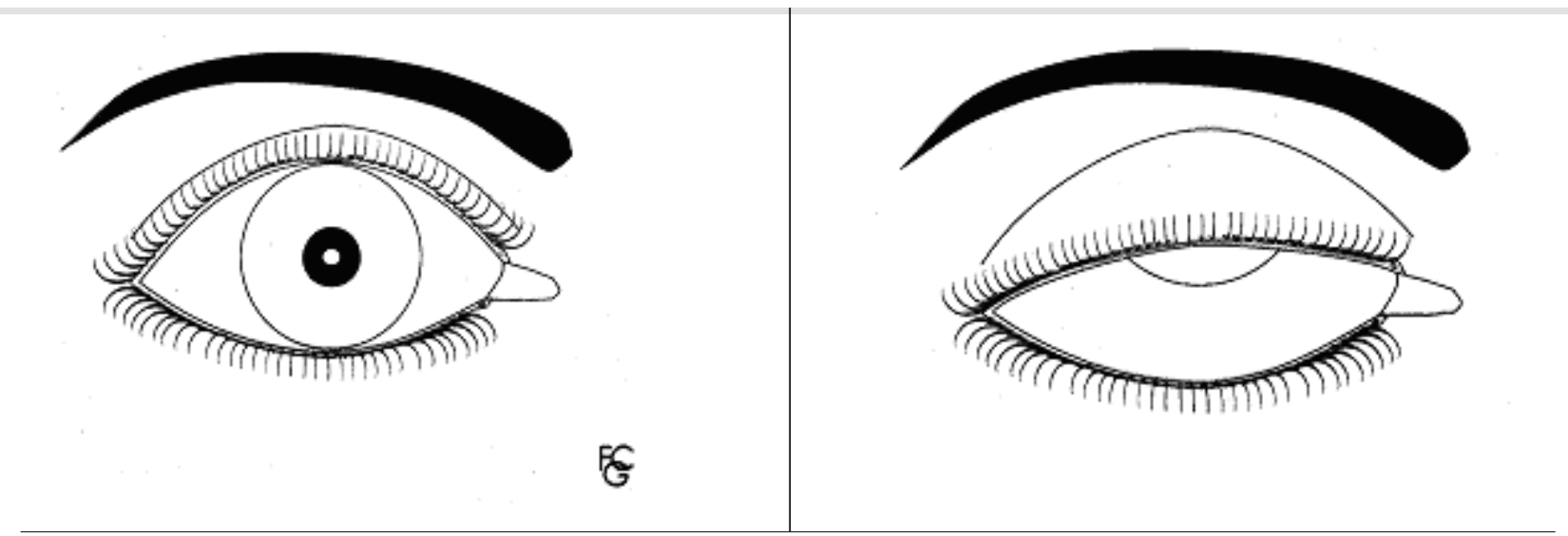

Figura 5 - Lagoftalmo: incapacidade de oclusão da fenda palpebral: à esquerda - paciente olhando para a frente (nas paralisias do orbicular, freqüentemente a pálpebra superior apresenta discreta retração); à direita - na tentativa de oclusão da fenda, a pálpebra superior não desce completamente. 
No lagoftamo cicatricial, na maioria das vezes, o orbicular é normal, pois são os processos restritivos que impedem a descida da pálpebra superior.

O lagoftalmo paralítico é muito mais comum que o cicatricial. O caso típico é o representado pela paralisia facial periférica ${ }^{1}$. Dependendo do grau de hipofunção do orbicular, a oclusão da fenda pode ser impossível. Nessas condições, a interação entre o grau de deficiência do orbicular e a magnitude do fenômeno de Bell (rotação superior dos olhos durante a oclusão da fenda palpebral) é que vai ditar a gravidade do quadro, podendo haver desde epífora até perfuração corneana e amaurose. Nos casos mais graves, o lagoftamo é uma urgência oculoplástica e exige procedimentos cirúrgicos emergenciais como a tarsorrafia.

Embora o reestabelecimento tardio da dinâmica palpebral possa ser feito de várias maneiras ${ }^{23}$, o procedimento mais simples e eficaz é a inserção cirúrgica de um peso de ouro de cerca de $1 \mathrm{~g}$ na face anterior da placa tarsal ${ }^{24 / 26}$.

Como a tensão do orbicular é um dos fatores de manutenção da posição da pálpebra inferior, lagoftalmos paralíticos de longa duração cursam com ectrópio da pálpebra inferior, condição que não deve ser confundida com lagoftalmo e que será abordada adiante.

\subsection{4 - Blefaroespasmo}

O blefaroespasmo é uma condição polar em relação ao lagoftalmo paralítico. Enquanto que esse último decorre de deficiência inervacional do orbicular, que impede a oclusão da fenda, no blefarospasmo, contrações espásticas do orbicular ocluem a fenda palpebral involuntariamente por períodos de tempo variáveis $^{27 / 29}$. Dependendo da intensidade da doença, o paciente pode ficar funcionalmente cego e completamente impossibilitado de exercer uma atividade normal.

O blefaroespasmo é sempre bilateral, e pode ser isolado ou fazer parte de quadros distônicos mais amplos, como a síndrome de Meige ou a distonia oromandibular $^{30}$. O diagnóstico diferencial deve incluir o hemiespasmo facial, a apraxia da abertura palpebral e os quadros funcionais ${ }^{30}$.

A etiologia do blefaroespasmo é obscura, mas todas as evidências apontam para um processo central relacionado ao núcleo do nervo facial. Inúmeros tratamentos médicos e cirúrgicos foram propostos, no passado, para o controle dessa condição. Atualmente, os tratamentos de escolha são o uso da toxina botulínica A e a cirurgia miectomia do orbicular, corrugador e piramidal ${ }^{30}$.

\section{2 - Anomalias marginais posicionais}

Os principais fatores condicionantes da posição da margem palpebral são: a) ligamentos palpebrais medial e lateral; b) músculo orbicular; c) retratores (na pálpebra superior, o elevador palpebral, e, na inferior, a fáscia cápsulopalpebral); c) pele; d) tarso; e) conjuntiva e f) globo.

Algumas alterações, isoladas ou combinadas, das estruturas supramencionadas podem provocar eversões (ectrópio) ou inversões (entrópio) das margens palpebrais.

\subsection{1 - Ectrópios}

Condição caracterizada pela eversão da margem palpebral inferior ou superior (Figura 6). Os ectrópios são classificados nas seguintes formas clínicas: a) congênito, b) senil ou involutivo, c) paralítico, d) cicatricial e e) mecânico ${ }^{31 / 37}$.

A forma congênita é muito rara e de etiologia variada. O ectrópio senil é bastante comum, e só ocorre na pálpebra inferior devido a frouxidão ligamentar lateral e/ou medial. É discutido o papel da desinserção dos retratores nessa forma de ectrópio. O paralítico aparece nas paralisias de longa duração do VII nervo, traduzindo a perda de tono do músculo orbicular. Tam-

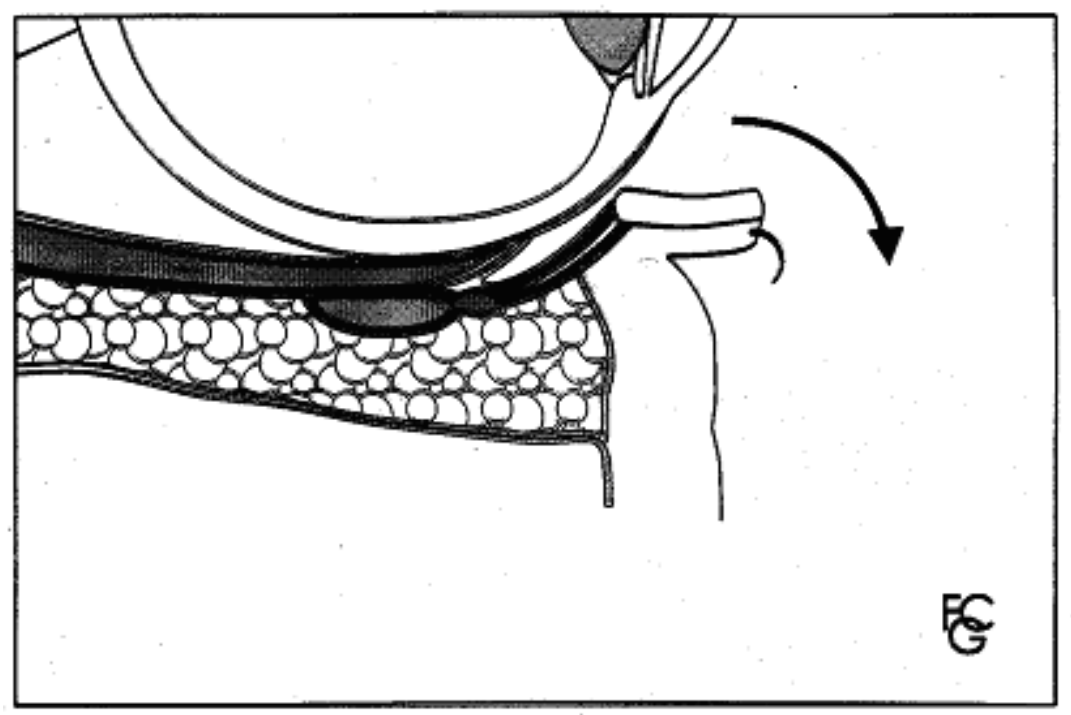

Figura 6 - Ectrópio da pálpebra inferior: eversão da margem palpebral. 
bém é restrito à pálpebra inferior. $\mathrm{O}$ ectrópio cicatricial pode acometer tanto a pálpebra superior como a inferior. Ele é devido a um déficit vertical de lamela anterior que everte a margem. Esse tipo de problema é comumente visto após traumas, queimaduras, exposição solar crônica e cirurgias palpebrais. Finalmente, a forma mecânica é a que ocorre, quando uma lesão bulbar empurra a margem palpebral, evertendo-a ${ }^{33}$.

Todos os ectrópios são abordados cirurgicamente. Os procedimentos vão depender dos fatores causais, variando de acordo com a forma clínica.

\subsection{2 - Entrópios}

Condição caracterizada pela inversão da margem palpebral inferior ou superior (Figura 7). Os entrópios são classificados nas seguintes formas clínicas: a) congênito, b) espástico, c) senil ou involutivo, d) cicatricial e e) mecânico ${ }^{38 / 44}$.

O entrópio congênito é bastante raro. Freqüentemente tem um componente espástico, devendo, pois, inicialmente, ser abordado conservadoramente. Ele deve ser diferenciado do epibléfaro inferior, que é uma prega cutânea horizontal, congênita, que direciona os cílios para cima. No epibléfaro, a margem está normalmente posicionada e todo o problema restringe-se a um excesso de lamela anterior. O entrópio espástico acomete os adultos, sendo, caracteristicamente, transitório e recorrente. Ele ocorre pelo aumento do tono do orbicular pré-septal. O entrópio senil é um dos mais comuns. Na sua etiologia, imbricam-se, em graus

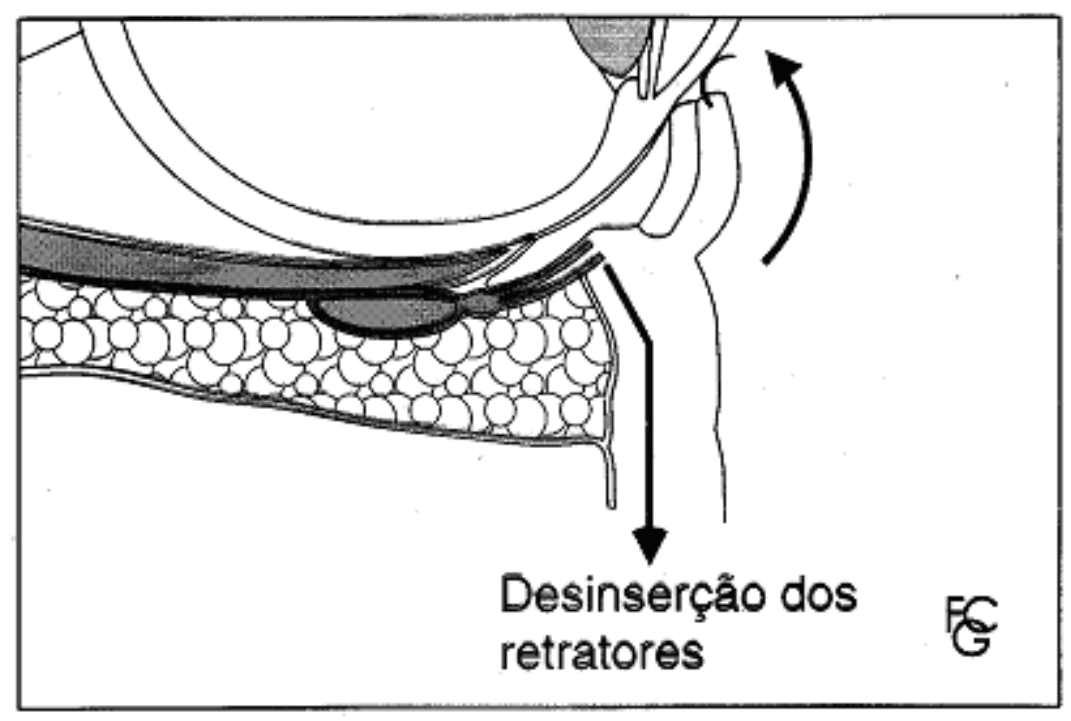

Figura 7 - Entrópio da pálpebra inferior: inversão da margem palpebral. A desinserção dos retratores é comum nos entrópios involutivos. variáveis, três fatores: frouxidão ligamentar, atenuação ou desinserção dos retratores e hiperação do orbicular pré-septal. O entrópio cicatricial pode acometer tanto a pálpebra superior como a inferior. Em Ribeirão Preto, a grande maioria dos casos de entrópio cicatricial é de origem tracomatosa. No tracoma, a contração da conjuntiva e do tarso da pálpebra superior invertem a margem palpebral, causando entrópio e triquíase (ver adiante). Finalmente, o exemplo típico de entrópio mecânico é dado pela má adaptação de próteses oculares que provocam a inversão da margem. A anoftalmia por si só já é um fator mecânico indutor de entrópio.

Como nos ectrópios, o tratamento da maioria das formas de entrópio é cirúrgico.

\section{3 - Anomalias marginais ciliares}

As anomalias ciliares constituem um grupo de condições mal definido terminologicamente, porém de grande importância clínica. Qualquer uma das formas descritas adiante pode provocar dano permanente à córnea e baixa visual definitiva ${ }^{42,45 / 49}$.

\subsection{1 - Triquíase}

O termo triquíase, origina-se do grego trichos (cabelo) e significa mal direcionamento dos cílios que perdem o direcionamento normal e tocam a córnea.

\subsection{2 - Distiquíase}

Distiquíase é um vocábulo também originário do grego, cuja raiz é distichos (duplo). Designa uma condição congênita ou adquirida, caracterizada pelo aparecimento de neocílios posteriores à linha cinzenta, ou seja, na lamela posterior.

O termo "distriquíase" não é usado e deve ser evitado.

\subsection{3 - Ptose ciliar}

É uma condição, não muito rara, mas que só modernamente tem sido reconhecida. Ela é caracterizada pela perda da orientação de todos ou de grande parte dos cílios da pálpebra superior, que adotam uma forma retilínea e dirigemse para baixo, podendo ou não tocar a córnea. Um mecanismo produtor de ptose ciliar é a atonia da lamela anterior, comumente vista nas hipofunções do orbicular superior (Figura 8).

$\mathrm{O}$ tratamento das anomalias ciliares está indicado, quando os cílios tocam 
a córnea. Nesses casos, várias modalidades terapêuticas podem ser usadas: epilação com radiofreqüência ou crioterapia, ressecções palpebrais em bloco, enxertos de mucosa labial, etc. Como há uma tendência à recidiva, o acompanhamento biomicroscópico pós-operatório deve ser mantido por longo período de tempo.
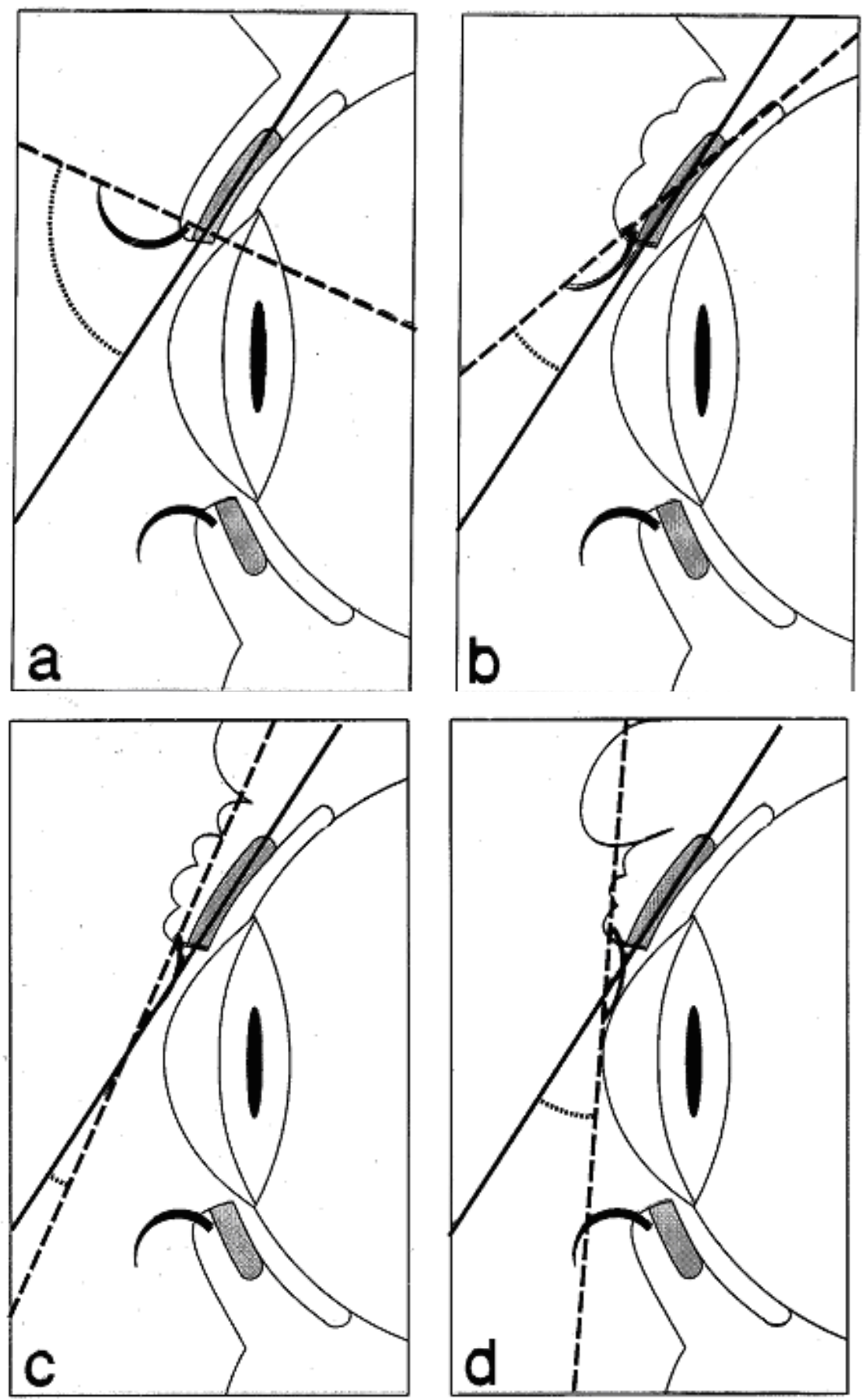

Figura 8 - Conceito de ptose ciliar: a) orientação normal dos cílios da pálpebra superior, b e c) rotação inferior, global, dos cílios por atonia da lamela anterior, d) toque corneano.

\section{4 - Infecções}

As pálpebras, como qualquer outro território cutâneo, podem ser sítio de infecções virais, fúngicas e bacterianas, as mais diversas ${ }^{50}$.

O principal exemplo de acometimento viral palpebral é o do Herpes Zoster oftálmico, cujo diagnóstico clínico, em geral, não apresenta problema, pois é típico o aparecimento de vesículas ao longo do trajeto de um dos ramos da primeira divisão do trigêmio.

O Herpes simplex, principalmente o do tipo 1, também pode acometer as pálpebras, em geral, sob a forma de blefarite ulcerativa ou de lesões isoladas ${ }^{50}$.

Infecções cutâneas bacterianas podem gerar celulite préseptal. Esse termo (celulite pré-septal), tem o mesmo significado descritivo de abscesso palpebral, devendo ser diferenciado das celulites pós-septais ou orbitais (ver celulites orbitárias). As infecções bacterianas mais comuns são as que acometem as glândulas palpebrais $^{51}$. Na pálpebra, existem duas glândulas associadas aos cílios: as de Moll, sudoríparas modificadas, e as de Zeiss, sebáceas. Ambas podem ser infectadas por bacterias (tipicamente, estafilococos) e produzirem os chamados hordeólos externos. Quando a infeção acomete as glândulas, sebáceas, intra-tarsais de Meibomius, há o aparecimento do hordeólo interno. O acometimento das glândulas de Meibomius pode ser difuso e envolver todo o tarso (tarsite).

A paracoccidiodomicose pode envolver as pálpebras, primariamente, ou no contexto de um acometimento mucocutâneo generalizado. As lesões são bastante destrutivas e simulam neoplasias.

\section{5 - Neoplasias}

Neoplasias, malignas ou benignas, de qualquer linhagem tecidual, podem aparecer nas 
pálpebras ${ }^{52}$. O tumor palpebral mais freqüente é o carcinoma basocelular (CBC). Freqüentemente associado a alterações cutâneas actnícas, o CBC atinge, preferencialmente, a pálpebra inferior e a região do canto medial. Lesões laterais e superiores são menos encontradas. O CBC pode aparecer sob inúmeras formas clínico-histológicas (nodular, ulcerativa, esclerosante, multicêntrica) ${ }^{53}$ e, dependendo da localização, constituírem grandes problemas cirúrgicos. Não é incomum, no setor de oculoplástica do HCFMRP-USP, a indicação de exenteração orbital devido a invasão da órbita por $\mathrm{CBC}$, inicialmente restrita à região periocular.

O carcinoma espinocelular (CEC) é muito menos freqüente que o CBC. Clinicamente, eles aparecem como lesões ulceradas, às vezes, com características de ceratoses actínicas. O potencial metastatizante dos CEC é baixo, porém a morbidade piora em áreas previamente irradiadas ${ }^{53}$.

Um tumor maligno não muito comum, mas clinicamente importante, é o carcinoma sebáceo. Originando-se de uma glândula de Meibomius, ele frequientemente é confundido com um calázio recidivante. A perda de cílios e a distorção da margem palpebral devem alertar o médico para a possibilidade do carcinoma sebáceo.

\section{2. ÓRBITAS}

\subsection{Síndromes inflamatórias agudas}

Clinicamente, as síndromes inflamatórias agudas da órbita caracterizam-se pelo início súbito de dor óculoorbitária, em geral constante, e que se exacerba à movimentação do globo ocular. Todos os anexos orbitários podem estar envolvidos, em maior ou menor extensão. Assim sendo, as pálpebras estão, em geral, edemaciadas, hiperemiadas e com aumento da temperatura local, havendo, freqüentemente, ptose mecânica, devido ao edema. A conjuntiva mostra-se hiperemiada e quemótica, ocorrendo, muitas vezes, protusão e exposição da mesma, o que impede um fechamento completo da fenda palpebral. Ao nível da glândula lacrimal, pode haver tumefação e aumento da sensibilidade local.

Ao exame clínico, os principais achados são a proptose (Figura 9) e a limitação da motricidade ocular, além das alterações de anexos descritas acima. A direção da proptose pode fornecer indícios da sede do processo inflamatório. Desse modo, um deslocamento do globo ocular, para baixo e medialmente, sugere processo inflamatório da glândula lacrimal (de localização súpero-temporal). Se a proptose for intensa, há lesão corneana devido à exposição da mesma. A
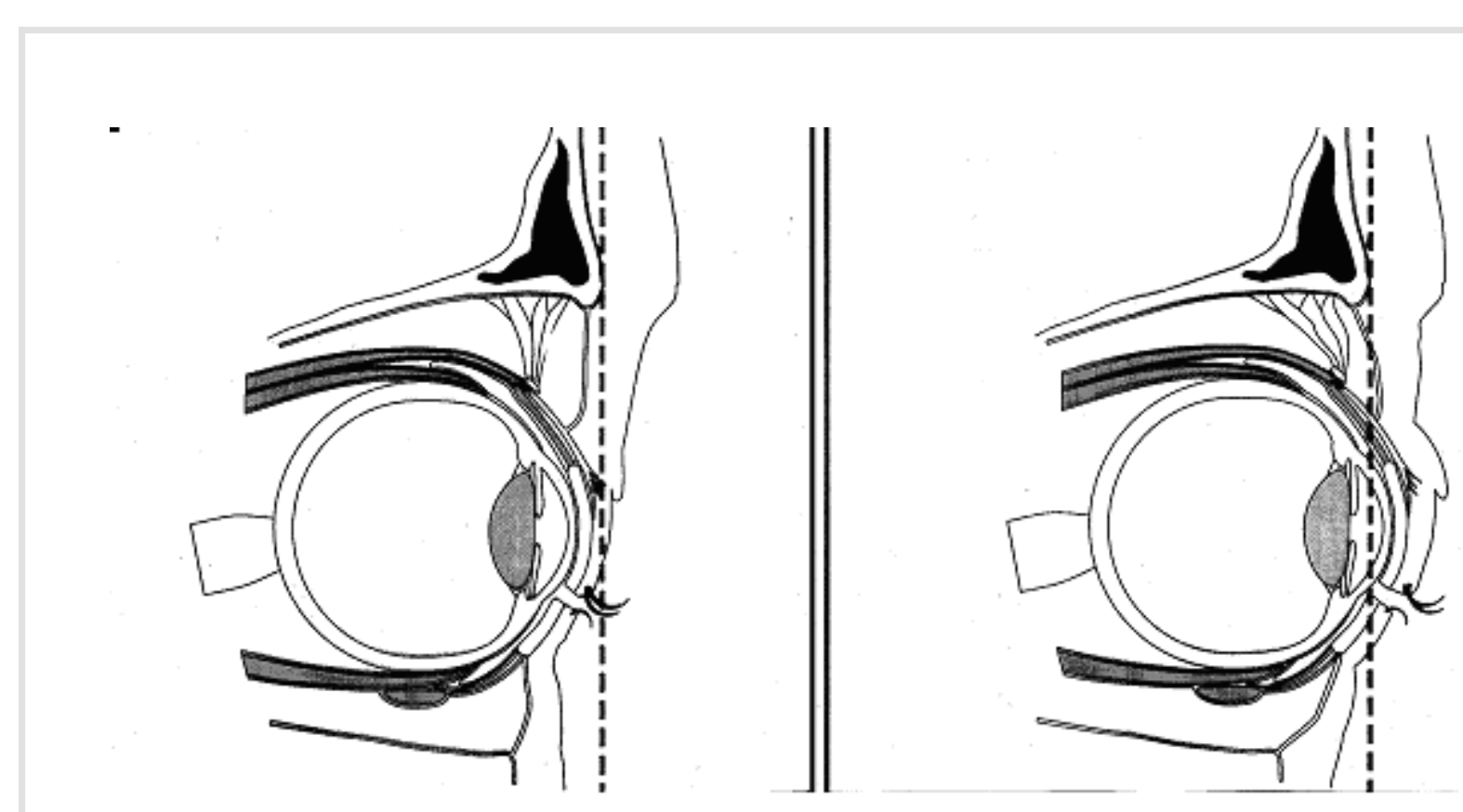

Figura 9 - Conceito de proptose ou exoftalmia: à esquerda - olho normalmente posicionado em relação ao rebordo orbital, à direita: - deslocamento anterior do olho. 
motilidade ocular freqüentemente está afetada, havendo maior limitação, quando se tenta deslocar o globo ocular na direção da sede do processo inflamatório. Na dependência da intensidade e extensão do processo, a função visual pode estar comprometida.

Apesar de inúmeros processos patológicos manifestarem-se, como síndrome inflamatória aguda da órbita, dicutiremos, a seguir, apenas os quadros mais frequientes da prática clínica: as celulites e os pseudotumores inflamatórios.

\subsection{1- Celulites}

Denomina-se celulite orbitária o processo infeccioso dos tecidos orbitários, de etiologia variada (bacteriana, viral, fúngica, etc) ${ }^{54 / 62}$. Nesse sentido, celulite orbitária tem o mesmo signficado de celulite pós-septal. $\mathrm{O}$ agente etiológico, geralmente, alcança a órbita por contigüidade, a partir dos seios paranasais, da própria face (infecção cutânea) ou da orofaringe. As celulites secundárias à septicemia ou a corpo estranho orbital são bem mais raras. Na grande maioria dos casos, as celulites orginam-se das sinusites. Em crianças, a celulite orbitária é a principal causa de proptose uni ou bilateral.

As celulites podem aparecer sob a forma de abscesso subperiósteo, abscesso orbitário e celulite difusa. Além da anamnese e do exame físico, a tomografia computadorizada tem importância fundamental no diagnóstico da celulite orbitária, ao mostrar, claramente, a localização e a extensão do processo infeccioso, permitindo não só a classificação como o estadiamento da evolução do quadro.

Uma vez aventada a hipótese de celulite orbitária de origem bacteriana, tratamento imediato com antibioticoterapia endovenosa deve ser instituído, a fim de se evitar a progressão da infecção e complicações neurológicas, potencialmente letais (ex. abscesso cerebral, trombose de seio cavernoso). Abscessos intraconais são muito mais perigosos que os subperiósteos, pela proximidade da fissura orbital superior. A escolha do antibiótico adequado é um assunto controverso. Em geral, utiliza-se antibióticos de largo espectro. Quando associada à sinusite, os principais microrganismos encontrados são: Staphilococus ( $S$. aureus, $S$. epidermides), Streptococus, Diphteroides, $H$. influenzae (crianças), E. coli, Pseudomonas. Nos adultos, é comum o crescimento polimicrobiano anaeróbio e aeróbio e, em crianças abaixo de quatro anos de idade, o do $H$. influenzae. A partir da instituição da terapêutica, uma melhora geral do quadro é esperada em 48-72 hs, caso contrário deve-se suspeitar da formação de abscesso orbitário com provável indicação de dre- nagem cirúrgica da órbita. Quando comparadas às celulites das crianças, as celulites dos adultos apresentam, mais freqüentemente, necessidade de intervenções cirúrgicas para drenagem orbitária e dos seios, bem como maior porcentagem de complicações neurológicas.

\subsection{2- Síndromes inflamatórias idiopáticas (pseudotumores inflamatórios da órbita )}

Define-se pseudotumor de órbita como o processo inflamatório dos tecidos orbitários, uni ou bilateral, de etiologia autoimune. Portanto, pela própria definição, trata-se de um diagnóstico de exclusão, devendo-se descartar outras patologias locais (ex. cisto dermóide roto) ou sistêmicas (ex. poliarterite nodosa), que predispõem ou podem se manifestar como inflamação orbitária aguda ${ }^{63 / 67}$.

De acordo com a localização do processo, os pseudotumores são classificados em: a) lacrimal: a glândula lacrimal é a sede da inflamação; b) anterior: o processo inflamatório localiza-se junto à porção posterior do globo ocular, c) miosítico: a sede da inflamação são os músculos extra-oculares, d) difuso: a inflamação acomete os tecidos orbitários de forma difusa e e) apical: a inflamação localiza-se no ápice da órbita.

O pseudotumor orbitário acomete, igualmente, homens e mulheres, sendo a bilateralidade mais comum em crianças. Clinicamente, o principal diagnóstico diferencial é feito com a celulite orbitária.

Os achados tomográficos dependem da forma clínica. Geralmente, há um apagamento da gordura orbital de densidade heterogênea, devido às alterações teciduais que acompanham o processo inflamatório. Um sinal radiológico extremamente importante é o borramento da esclera posterior.

Histologicamente, observa-se infiltrado celular polimórfico (linfócitos, plasmócitos e eosinófilos), edema, dilatação vascular e fibrose, sendo esta última tanto mais extensa quanto maior a duração do processo.

O tratamento consiste na administração de corticóide via oral (meticortem 60-80 mg/dia, com diminuição progressiva da dose), havendo, nas formas agudas, dramática resposta ao tratamento, com grande melhora do quadro em 48-72 hs.

\section{2- Doenças linfoproliferativas}

Em condições normais, os linfócitos podem ser encontrados na substância própria da conjuntiva e espalhados, em pequeno número, entre os ácinos da glândula lacrimal, não havendo nos demais tecidos orbitários linfonodos ou linfócitos. Portanto, qualquer massa intra-orbitária de tecido linfóide é anormal. 
Estudos recentes têm demonstrado que as hiperplasias linfóides reacionais e os linfomas não diferem quanto ao grupo etário que acometem, ao tipo de sintomas que provocam ou à duração desses sintomas. Deste modo, torna-se praticamente impossível diferenciar estas duas patologias, somente em bases clínicas.

As doenças linfoproliferativas apresentam início insidioso (sem sinais de inflamação orbitária) e acometem, principalmente, os adultos entre 50-70 anos de idade. Em geral, há proptose moderada (menor que $5 \mathrm{~mm}$ ), alteração discreta da motricidade ocular e, ocasionalmente, diminuição da acuidade visual. As lesões tendem a ocorrer mais freqüentemente na órbita superior e anterior, sendo a glândula lacrimal o sítio de envolvimento mais frequiente ( $30 \%$ dos casos).

À tomografia, verifica-se um velamento homogêneo, que, tipicamente, molda o globo ocular, sem comprimi-lo e sem provocar erosão óssea das paredes orbitárias. A classificação das lesões linfóides, muitas vezes, só é possível com o estudo imunohistoquímico.

\subsection{1- Hiperplasias linfóides reacionais}

De acordo com o grau de atipia celular, são divididas em hiperplasias linfóides reacionais típicas e atípicas $^{68 / 71}$.

A hiperplasia típica tem como características principais a presença de linfócitos pequenos, escuros, sem atividade mitótica significativa, com organização folicular de formas irregulares. A população celular é polimórfica (plasmócitos, histiócitos e, às vezes, eosinófilos). O estudo imunohistoquímico revela população celular policlonal.

A hiperplasia atípica apresenta células com padrão monótono, podendo haver folículos remanescentes. O estudo imunohistoquímico pode ser inconclusivo.

\subsection{2- Linfomas}

Histologicamente, os linfomas podem apresentar padrão de crescimento nodular ou difuso (maioria dos casos). A população celular é sempre monótona, com padrão imunohistoquímico monoclonal ${ }^{68 / 77}$.

\section{3 - Orbitopatia distireoidiana}

A orbitopatia distireoidiana é uma patologia auto-imune orbital, que pode estar associada à Tireoidite de Hashimoto, eutireoidismo ou ao Bócio Difuso Tóxico e conseqüente hipertireoidismo. Essa última eventualidade caracteriza a doença de Basedow-Graves ou, simplesmente, Graves, descrita no século XIX, quando esses autores relacionaram proptose e aumento difuso da tireóide ${ }^{10,78 / 82}$.
A doença de Graves é a variante mais freqüente da orbitopatia distiroidiana, ocorrendo em cerca de $90 \%$ dos casos. Essa preponderância do hipertireoidismo é de tal monta, que a maior parte das publicações considera a expressão, doença de Graves, como sinônimo de orbitopatia distireoidiana. Outras denominações são ainda usadas como oftalmopatia de Graves e doença orbital relacionada à tireóide.

Uma noção importante é a que dissocia o quadro orbital do endocrinológico. Não são os hormônios da tireóide (T3 e T4) que causam a orbitopatia. Tanto a órbita quanto a tireóide são órgãos de choque de um processo auto-imune celular e humoral. A doença orbital segue um curso próprio não paralelo à normalização dos níveis séricos de T3 e T4.

$\mathrm{Na}$ órbita, as principais estruturas acometidas são o tecido conectivo muscular e a gordura orbital. Nesses tecidos, o infiltrado linfoplasmocitário implica em acúmulo de glicosaminoglicanos e água. Conseqüentemente, ocorre proptose e miopatia restritiva, levando a limitação das rotações oculares e diplopia.

O envolvimento dos elementos retratores das pálpebras superior (músculo de Müller e elevador palpebral) e inferior (músculo tarsal inferior e fáscia cápsulopalpebral/reto inferior), na doença orbital, explica a altíssima prevalência de retração palpebral na orbitopatia distireoidiana.

Testemunho da alta frequiência do envolvimento palpebral na doença de Graves é o grande número de epônimos relacionados a esse tipo de acometimento $\left(\right.$ Tabela I) ${ }^{83}$.

\begin{tabular}{|c|c|}
\hline Epônimo & Significado \\
\hline Dalrymple & Retração palpebral \\
\hline Boston & $\begin{array}{l}\text { Movimento para baixo, em roda den- } \\
\text { teada, da pálpebra superior, na infra- } \\
\text { versão }\end{array}$ \\
\hline Enroth & Edema da pálpebra inferior \\
\hline Gifford & $\begin{array}{l}\text { Dificuldade na eversão da pálpebra } \\
\text { superior }\end{array}$ \\
\hline Griffith & $\begin{array}{l}\text { Lag da pálpebra inferior, no olhar para } \\
\text { cima }\end{array}$ \\
\hline Jellinek & Pigmentação palpebral \\
\hline Mean & $\begin{array}{l}\text { Aumento do scleral show superior em } \\
\text { supraversão }\end{array}$ \\
\hline Ponchin & Redução da amplitude do piscar \\
\hline Rosembach & Tremor palpebral, na oclusão da fenda \\
\hline Stellwag & Diminuição da freqüência do piscar \\
\hline $\begin{array}{l}\text { Vigouroux } \\
\text { von Graeffe }\end{array}$ & $\begin{array}{l}\text { Aumento das partes moles palpebrais } \\
\text { Laq da pálpebra superior, na infraversão }\end{array}$ \\
\hline
\end{tabular}


Em recente estudo realizado no Hospital das Clínicas da Faculdade de Medicina de Ribeirão Preto, de 86 pacientes com orbitopatia de Graves (todos tinham BDT) $53,48 \%$ apresentavam proptose + retração palpebral, 30,23\% somente retração, 11,62 somente proptose e $4 \%$, outras alterações da orbitopatia, como edema palpebral, aumento da gordura pré-aponeurótica etc. Assim, 83,7\% dos pacientes apresentavam retração. Dentre estes, a retração era superior em $70,8 \%$ dos casos (48,6\% bilateral e $22,2 \%$ unilateral), superior e inferior em $22,2 \%$ (20,8 bilateral e $1,3 \%$ unilateral) e unicamente inferior em 6,9\% da amostra (5,5\% bilateral e $1,3 \%$ unilateral).

\section{4 - Fraturas}

No amplo espectro das fraturas faciais, as orbitais constituem um grupo bem individualizado, em virtude de freqüentemente estarem associadas à lesão motora ou sensorial ocular.

Existe uma enorme variabilidade na apresentação clínica das fraturas orbitais. Não obstante, elas podem ser divididas em 4 grupos: internas (blow-out, blow-in), zigomatico-orbitais, nasoetmoidoorbitais e complexas ou combinadas ${ }^{84}$.

As fraturas internas mais comuns são as do tipo blow-out, ou seja, fratura limitada a uma das paredes orbitais, não atingindo o rebordo, cujo fragmento se desloca para fora da órbita. As mais frequientes envolvem o assoalho orbital, mas as de parede medial também são comuns. As fraturas do teto, comumente, são do tipo blow-in (fragmento ósseo) deslocado para o interior da órbita.

As fraturas zigomaticoorbitais, provavelmente, são as mais comuns de todas as fraturas orbitais. Dependendo do grau de acometimento do zigomático, elas podem ser subdivididas em vários tipos: zigomático deslocado ou não, cominutivamente fraturado, etc.

As nasoetmoidoorbitais são fraturas mais complexas devido à tridimensionalidade da região. Elas resultam de impactos na linha média e provocam, dependendo da gravidade, achatamento do nariz e telecanto.

Se não reparadas, a maioria das fraturas orbitais produz enoftalmo, devido ao aumento do continente orbitário. É freqüente o desenvolvimento de estrabismo restritivo, o que causa diplopia. A lesão do nervo infra-orbitário e hipoestesia, no seu território, são comuns nas fraturas que envolvem o assoalho orbital.

Dependendo do grau de acometimento apical, qualquer fratura orbital pode lesar o nervo óptico e produzir déficit sensorial, que pode variar, desde pequenas alterações de percepção cromática até amaurose.

\section{5- Neoplasias não linfóides}

A órbita é sede de numerosos processos neoplásicos, benignos e malignos, apresentando enorme variação de tipos histológicos. Excelentes revisões sobre $\mathrm{o}$ assunto podem ser encontradas em livros textos ${ }^{85}$.

Em termos gerais, a avaliação clínica deve ser conduzida no sentido de se determinar se o processo é benigno ou maligno, e se seu comportamento é infiltrativo ou não infiltrativo.

Clinicamente, as lesões benignas, não-infiltrativas, manifestam-se por seu efeito de massa (proptose), sem provocar destruição tecidual ou dano funcional e, à tomografia, revelam margens regulares e bem definidas. Por outro lado, as lesões malignas e infiltrativas provocam dano funcional (visual, motor ou sensitivo), e margens irregulares à tomografia.

Quanto à topografia, os tumores podem ser classificados em intraconais, extraconais e difusos. Os principais tipos são:

\section{Tumores Intraconais}

O principal diagnóstico diferencial é feito entre o glioma do nervo óptico e o meningeoma da bainha do nervo. $\mathrm{O}$ glioma acomete principalmente crianças (média de 6 anos de idade), enquanto o meningeoma acomete mulheres de meia-idade. Ambos provocam proptose mínima (não mais que $2 \mathrm{~mm}$ ) e perda visual significativa, sendo esta mais precoce nos gliomas. A tomografia pode fornecer dados que sugerem a etiologia da lesão. Assim, espessamento fusiforme e de mesma densidade do nervo, margens regulares e ausência de erosão óssea ou hiperostose sugerem glioma. Por outro lado, espessamento discreto e de densidade diferente do nervo, margens irregulares, erosão óssea ou hiperostose sugerem meningeoma.

\section{Tumores da Glândula Lacrimal (Extraconais)}

Os principais dados de anamnese, na avaliação de um aumento da glândula lacrimal, são a duração dos sintomas e a presença ou ausência de dor. Os tumores epiteliais benignos (adenoma pleomórfico) manifestam-se por aumento progressivo da glândula, sem dor local. Acometem pacientes na faixa dos 30-40 anos, e, à tomografia, não há erosão óssea. Nos casos de longa duração, pode haver malignização do tumor, o que acarreta, em geral, dor local e crescimento acelerado da lesão.

Nem sempre os tumores malignos provocam dor. É comum encontrarem-se carcinomas adenóides císticos de longa duração, cuja única manifestação é o aumento da glândula. Nestes casos, pode haver erosão óssea e diplopia. 


\section{Rabdomiossarcoma (Difuso)}

Os rabdomiossarcomas constituem importante causa de proptose de rápida evolução nas crianças. É o tumor maligno orbitário mais freqüente no grupo pediátrico, sendo que $70 \%$ dos casos ocorrem na primeira década de vida. Em geral, há deslocamento do globo ocular para baixo e, temporalmente, edema palpebral, sendo a dor uma manifestação incomum. O tumor é mais freqüente no sexo masculino (proporção masculino/feminino de 5:3).

\section{Tumores Orbitários Metastáticos (Focais ou Difusos)}

No grupo pediátrico, os tumores metastáticos mais freqüentes são os neuroblastomas, e os sarcomas granulocíticos. Os primeiros acometem crianças com idade média de 2 anos, sendo bilaterais em $40 \%$ dos casos.

Os sarcomas granulocíticos surgem durante o curso da leucemia mielóide aguda ou leucemia mielóide crônica, em crise blástica. A idade média de apresentação é de 7 anos, sendo, a proptose, de aparecimento rápido.

Nos adultos, tem sido verificado um aumento da incidência de metástases orbitárias, à medida em que aumenta a sobrevida de pacientes portadores de neoplasias. Os sítios primários mais freqüentes são os pulmões e as mamas.

\section{Tumores locais}

A invasão orbital por neoplasias circunvizinhas é extremante freqüente. Pacientes com carcinomas e linfomas que se originam dos seios paranasais, normalmente, só procuram o médico, quando a neoplasia invade a órbita e provoca proptose.

No nosso meio, tumores palpebrais (CBC e CEC) com frequiência invadem a órbita.

\section{3 - VIAS LACRIMAIS}

\section{1 - Obstrução lacrimais}

Quando se instila uma gota qualquer no saco conjuntival, ela escoa para a região do canto medial (lago lacrimal) e, em seguida, é drenada, rapidamente, segundo uma função matemática complexa, de modo que cerca de $80 \%$ do fluido instilado desaparece do olho em menos de 1 minuto.

O sistema de drenagem lacrimal é um processo ativo, mediado pela função do orbicular, e conhecido com o nome de bomba lacrimal. A cinética da drenagem lacrimal depende não só da atividade contrátil do orbicular, como também da integridade anatômica do conjunto de estruturas que permitem que a película lacrimal seja constantemente renovada: as vias lacrimais ${ }^{86 / 89}$.

A vias lacrimais são constituídas pelas seguintes estruturas (Figura 10): pontos lacrimais (superior e inferior), canalículos lacrimais (superior e inferior); canalículo comum (nem sempre presente), saco lacrimal; ducto ou canal lácrimonasal ${ }^{89}$.

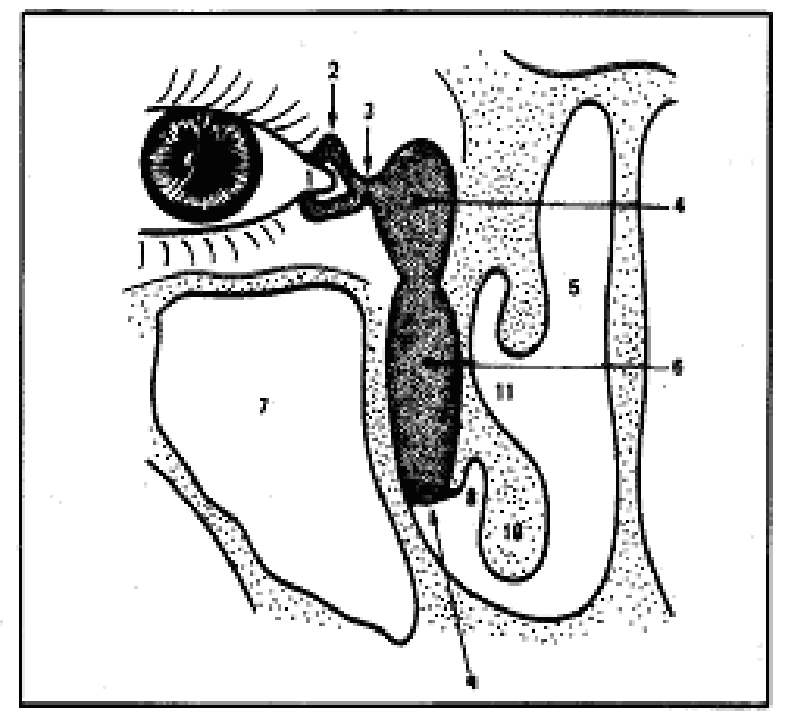

Figura 10 - Vias lacrimais: 1) lago lacrimal, 2) canalículo superior, 3) canalículo comum, 4) saco lacrimal, 5) cavidade nasal, 6) canal ou ducto nasolacrimal, 7) seio maxilar, 8) meato inferior, 9) abertura do canal lácrimonasal, 10) corneto inferior, 11) meato médio.

Em qualquer nível do sistema de drenagem, pode haver obstrução. As obstruções altas são aquelas que acontecem no segmento horizontal das vias lacrimais, isto é, entre os pontos e o saco lacrimal. As baixas acontecem no segmento vertical das vias lacrimais, ou seja, no canal lácrimonasal ${ }^{90,91}$.

Embora a primeira conseqüência de qualquer um dos dois tipos de obstrução seja a mesma (estase lacrimal ou epífora), eles se diferenciam em vários aspectos. As obstruções baixas cursam com dilatação do saco lacrimal, refluxo positivo à compressão da região cantal medial, freqüente desenvolvimento de infecções no saco lacrimal (dacriocistites). As altas não induzem dilatação do saco lacrimal, o refluxo é negativo e, normalmente, não são acompanhadas de dacriocistites. 
A terapêutica cirúrgica também varia segundo a localização da obstrução. As baixas são corrigidas pela dacriocistorrinostomia, cirurgia que consiste na derivação do saco lacrimal para o interior da cavidade nasal, ao nível do meato médio. As altas exigem ou intubação das vias com silicone ou o emprego de próteses lacrimais, como o tubo de Lester Jones.

As obstruções lacrimais, altas ou baixas, podem ser congênitas ou adquiridas. As congênitas altas são exemplificadas pelas imperfurações ou mesmo ausência dos pontos lacrimais. Muito mais freqüentes são as congênitas baixas, caracterizada pela presença de uma membrana embrionária na abertura do canal lacrimonasal no meato inferior. Este tipo de obstrução, em $90 \%$ dos casos, desaparece espontaneamente. Quando o problema não desaparece até a idade de 1 ano, o sistema é, inicialmente, sondado e, eventualmente, operado (dacriocistorrinostomia).

As obstruções altas adquiridas, geralmente, acontecem devido a trauma na região medial da fenda palpebral ou estenose canalicular (viroses, radioterapia, uso de drogas tópicas). As adquiridas baixas estão relacionadas às fraturas nasais, infecções conjuntivais ou aparecem na velhice, sem causa aparente.

\section{2 - Dacriocistites}

As dacriocistites ou infecções do saco lacrimal, representam complicações das obstruções baixas não tratadas. Elas podem ser crônicas ou agudas. As crônicas são caracterizadas por dilatação do saco lacrimal, refluxo positivo com secreção mucóide ou mucopurulenta. Esses achados podem persistir inalterados por longo período de tempo e, repentinamente, evoluírem para um abscesso do saco lacrimal. É a dacriocistite aguda, que exige antibioticoterapia sistêmica e, em alguns casos, drenagem do saco lacrimal. Nas duas formas, o único tratamento definitivo é a dacriocistorrinostomia ${ }^{91}$.

CRUZ AAV; CHAHUD F \& GUIMARÃES FC. Ocular adnexal pathology. Medicina, Ribeirão Preto, 30: 36-51, jan./march 1997.

ABSTRACT: The main topics of the adnexal ocular pathology were reviewed with emphasis in the pathologic conditions that belong to the oculoplastic field.

UNITERMS: Oculoplastic. Ocular Adnexa. Pathology.

\section{REFERÊNCIAS BIBLIOGRÁFICAS}

1 - SIBONY PA; EVINGER C \& MANNING KA. Eyelid movements in facial paralysis. Arch Ophthalmol 109: 1555-1561, 1991.

2 - SCHMIDTKE K \& BÜTTNER-ENNEVER JA. Nervous control of eyelid function. Brain 115: 227-247, 1992.

3 - CARRAWAY JH. Surgical anatomy of the eyelids. Clin Plast Surg 14: 693-701, 1987.

4 - CODÈRE F; TUCKER NA \& RENALDI B. The anatomy of whitnall ligament. Ophthalmology 102: 2016-2019, 1995.

5 - SIEGEL R. Surgical anatomy of the upper eyelid fascia. Ann Plast Surg 18: 263-273, 1984.

6 - JONES LT. The anatomy of the upper eyelid and its relation to ptosis surgery. Am J Ophthalmol 57: 943-959, 1964.

7 - FRALICK FB. Anatomy and physiology of the eyelid. Ophthalmology 66: 575-581, 1962.

8 - HAWES MJ; DORTZBACH RK. The microscopic anatomy of the lower eyelid retractors. Arch Ophthalmol 100: 1313-1318, 1982.
9 - SARVER BL \& PUTTERMAN AM. Margin limbal distance to determine amount of levator resection. Arch Ophthalmol 103: 354-356, 1985.

10 - FRUEH BR. Graves' eye disease: orbital compliance and other physical measurements. Trans Am Opthalmol Soc 82: 492-597, 1984.

11 - SMALL RG; SABATES NR \& BURROW D. The measurement and definition of ptosis. Ophthalmic Plast Reconstr Surg 5: 171-175, 1989.

12 - NUNERY, WR \& CEPELA M. Levator function in the evaluation and management of blepharoptosis. Ophthalmol Clin North Am 4: 1-16, 1991.

13 - FRUEH BR. The mechanistic classification of ptosis. Ophthalmology 87: 1019-1021, 1980.

14 - BERKE RN \& WADSWORTH JAC. Histology of levator muscle in congenital and acquired ptosis. Arch Ophthalmol 53: 413-428, 1955.

15 - CRAWFORD JS. Repair of ptosis using frontalis muscle and fascia lata. Trans Am Acad Ophthalmol Otolaryngol 60: 672-678, 1956. 
16 - BEARD C. Congenital ptosis. In: HORNBLASS A \& HANIG $\mathrm{CJ}$ eds. Oculoplastic, orbital and reconstructive surgery. Williams \& Wilkins, Baltimore, v. 1, p.119-141, 1988.

17 - DUTTON JJ. Etiology and classification of ptosis. In: DUTTON $\mathrm{JJ}$ ed. A color atlas of ptosis a pratical guide to evaluation and management. PG Publishing, Singapure, p. 1-9, 1989.

18 - ANDERSON RL \& DIXON RS. The role of whitnall's ligament in ptosis surgery. Arch Ophthalmol 97: 705-707, 1979.

19 - ANDERSON RL \& DIXON RS. Aponeurotic ptosis surgery. Arch Ophthalmol 97: 1129-1131, 1979.

20 - HARVEY JT \& ANDERSON RL. The aponeurotic approach to eyelid retraction. Ophthalmology 88: 513-524, 1981.

21 - ANDERSON RL. Age of aponeurotic awareness. Ophthalmic Plast Reconstr Surg 1: 77-79, 1985.

22 - SHORE JW. Changes in lower eyelid resting position, movement, and tone with age. Am J Ophthalmol 99: 415-423, 1985.

23 - ARION HG. Dynamic closure of the lids in paralysis of the orbicularis muscle. Int Surg 57: 48-50, 1972.

24 - LIU D. Gold Weight lid load as a secondary procedure. Plast Reconstr Surg 87: 854-858, 1991.

25 - SEIFF SR et al. Pretarsal fixation of gold weights in facial nerve palsy. Ophthalmic Plast Reconstr Surg 5: 104$108,1989$.

26 - Boerner M \& Seiff S. Etology and managemen of facial palsy. Curr Opin Ophthalmol 5: 61-66, 1994.

27 - SHORE JW. Coronal approach to protactor myectomy for essential blepharospasm. Adv Ophthalmic Plast Reconstr Surg 4: 333-347, 1985.

28 - SHORE JW. Essential blepharospasm. In: MCCORD JR. CD \& TANENBAUM M. eds. Oculoplastic surgery 2nd ed. Raven Press, New York, p. 475-491,1987.

29 - FRUEH BR; MUSCH DC \& BERSANI TA. Effects of eyelid protactor excision for the treatment of benign essential blepharospasm. Am J Ophthalmol 113: 681-686, 1992.

30 - WEINSTEIN GS \& ANDERSON RL. Blepharospasm: diagnosis and treatment In: HORNBLASS A \& HANIG CJ eds. Oculoplastic, orbital and reconstructive surger. Williams \& Wilkins, Baltimore, v. 1, p. 393-402, 1988.

31 - OESTREICHER JH \& NELSON CC. Lamellar Ichthyosis and congenital ectropion. Arch Ophthalmol 108: 1772-1773, 1990.

32 - HURWITZ JJ \& TUCKER S. Posterior horizontal and vertical tightening to treat combined punctal ectropion with medial canthal tendon laxity. Ophthalmic Surg 21: 721-725, 1990.

33 - FRUEH BR \& SCHOENGARTH LD. Evaluation and treatment of the patient with ectropion. Ophthalmology 89: 1049-1054, 1982.

34 - SMITH B. The lazy-T correction of ectropion of the lower punctum. Arch Ophthalmol 94: 1149-1150, 1976.

35 - WHITE JH. Method of correction of tarsal ectropion. Am J Ophthalmol 72: 615-617, 1971.
36 - BENGER RS \& FRUEH BR. Involutional ectropion: A review of the management. Ophthalmic Surg 18: 136-139, 1987.

37 - UTHOFF D; GORNEY M \& TEICHMANN C. Cicatricial ectropion in ichthyosis: A novel approach to treatment. Ophthalmic Plast Reconstr Surg 10: 92-95, 1994.

38 - BIGLAN AW \& BUERGER Jr. F. Congenital horizontal tarsal kink. Am J Ophthalmol 89: 522-524, 1980.

39 - NOWINSKI TS. Orbicularis oculi muscle extirpation in a combined procedure for involutional entropion. Ophthalmology 98: 1250-1256, 1991.

40 - BENGER RS \& MUSCH DC. A comparative study of eyelid parameters in involutional entropion. Ophthalmic Plast Reconstr Surg 5: 281-287, 1989.

41 - SCHAEFER AJ. Variation in the pathophysiology of involutional entropion and its treatment. Ophthalmic Surg 14: 653-655, 1983

42 - KERSTEN RC; KLEINER FP \& KULVIN DR. Tarsotomy for the treatment of cicatricial entropion with trichiasis. Arch Ophthalmol 110: 714-717, 1992.

43 - Al-RAJHI AA et al. The histopathology and the mechanism of entropion in patients with trachoma. Ophthalmology 100: 1293-1296, 1993.

44 - CRUZ AAV et al. Surgical correction of trachoma-related upper eyelid cicatricial entropion utilizing the barbera-carre technique. Ophthalmic plast reconstr surg 7: 269-271, 1991.

45 - SULLIVAN JH; BEARD C \& BULLOCK JD. Cryosurgery for treatment of trichiasis. Am J Ophthalmol 82: 117-121, 1976.

46 - SCHEIE H \& ALBERT DM. Distichiasis and trichiasis: origin and management. Am J Ophthalmol 61: 718-720, 1966.

47 - FEIN W. Surgical repair for distichiasis, trichiasis, and entropion. Arch Ophthalmol 94: 809-810, 1994.

48 - REACHER MH et al. A controlled trial of surgery for trachomatous trichiasis of the upper lid. Arch Ophthalmol 110: 667-674, 1992.

49 - BALLEN PH. A simple procedure for the relief of trichiasis and entropion of the upper lid. Arch Ophthalmol 72: 239-240, 1964.

50 - FRY CL \& NEUHAUS RW. Eyelid infections and inflammations. In: BOSNIAK S, ed. Principles and practice of ophthalmic plastic and reconstructive surgery, W.B. Saunders, Philadelphia, v. 1, p.307-322, 1996.

51 - WEINGEIST TA. The glands of ocular adnexa. Int Ophthalmol Clin 43: 243-261, 1973.

52 - SHORE JW \& BILYK JR. Clinical presentation, diagnosis, and treatment of eyelid tumors. Curr Opin Ophthalmol 2: 579-589, 1991.

53 - DOXANAS MT. Malignant epithelial eyelid tumors. In: BOSNIAK, $S$, ed. Ophthalmic plastic and reconstructive surgery, W.B. Saunders, Philadelphia, v. 1, p.342-351, 1996.

54 - WEISS A et al. Bacterial periorbital and orbital cellulitis in childhood. Ophthalmology 90: 195-203, 1983. 
55 - HARR DL; QUENCER RM \& ABRAMS GW. Computed tomography and ultrasound in the evaluation of orbital infection and pseudotumor. Radiology 142: 395-401, 1982.

56 - HARRIS GJ. Subperiosteal Inflammation of the orbit. Arch Ophthalmol 106: 947-952, 1988.

57 - SULLIVAN TJ; AYLWARD GW \& WRIGHT JE. Actinomycosis of the Orbit. Brit J Ophthalmol 76: 505-506, 1992.

58 - CLARY RA; CUNNINGHAM MJ \& EAVEY RD. Orbital complications of acute sinusitis: comparison of computed tomography scan and surgical findings. Ann Otol Rhinol Laryngol 101: 598-600, 1992.

59 - FACER GW \& KERN E. B.Sinusitis: Current concepts and management. In: BAILEY BJ, ed. Head and neck surgery-otolaryngology. Lippincott,JB, Philadelphia, p. 366-376, 1993.

60 - HARRIS GJ. Subperiosteal abscess of the orbit age as a factor in the bacteriology and response to treatment. Ophthalmology 101: 585-595, 1994.

61 - ROBERTS C; NYLANDER AE \& JAYARAMACHANDRAN S. Orbital cellulitis compllicating isolated unilateral sphenoidal sinusitis importance of the CT scan. Brit J Ophthalmol 73: 769-770, 1989.

62 - OTT NL et al. Childhood sinusitis. Mayo Clin Proc 66: 128-147, 1991.

63 - VOLPE NJ \& SHORE JW. Orbital myositis associated with herpes zoster. Arch Ophthalmol 109: 471-472, 1991.

64 - GOLDEBERG RA et al. Orbital inflammation and optic neuropathies associated with chronic sinusitis of intranasal cocaine abuse. Arch Ophthalmol 107: 831-835, 1989.

65 - SLAVIN ML \& GLASER JS. Idiopathic orbital myositis. Arch Ophthalmol 100: 1261-1269, 1982.

66 - HARRIS GJ et al. Orbital myositis as a Paraneoplastic Syndrome. Arch Ophthalmol 112: 380-386, 1994.

67 - LIPPA LM; JAKOBIEC FA \& SMITH M. Idiopathic inflammatory orbital pseudotumor in childhood. Ophthalmology 88: 565-574, 1981.

68 - ELLIS JH et al. Lymphoid tumors of the ocular adnexa. Ophthalmology 92: 1311-1324, 1985.

69 - ASTARITA RW et al. Orbital and adnexal lymphomas. Am J Clin Pathol 73: 615-621, 1980.

70 - JAKOBIEC FA et al. Ocular adnexal monoclonal lymphoid tumors with a favorable prognosis. Ophthalmology 93: 1547-1557, 1986.

71 - KNOWLES DM et al. Lymphoid hyperlasia and malignant lymphoma occurring in the ocular adnexa (Orbit, Conjuctiva, and Eyelids) A prospective multiparametric analysis of 108 cases during 1977 to 1987. Hum Pathol 21: 959-973, 1990.

72 - LAUER SA et al. Orbital T-cell lymphoma in human T-cell leukemia virus-I infection. Ophthalmology 95: 110-115, 1988.

73 - TUROK DI \& MEYER DR. Orbital lymphoma associated with acquired immunodeficiency syndrome. Arch Ophthalmol 110: 610-611, 1992.
74 - FONT RL et al. Malignant lymphoma of the ocular adnexa associated with the benign lymphoepithelial lesion of the parotid glands. Ophthalmology 99: 1582-1587, 1992.

75 - ANTLE CM et al. Large cell orbital Llymphoma in a patient with Acquired Immune Deficiency Syndrome. Ophthalmology 97: 1494-1498, 1990.

76 - JAKOBIEC FA; LEFKOWITCH J \& KNOWLESII DM. B- and T-lymphocytes in ocular disease. Ophthalmology 91: 635-654, 1984.

77 - REIFLER DM et al. Orbital lymphoma associated with Acquired Immune Deficiency Syndrome. Surv Ophthalmol 38: 371-380, 1994.

78 - SERGOTT RC \& GLASER JL. Graves' Ophthalmopathy. A clinical and Immunologic review. Surv Ophthalmol 26: 121, 1981.

79 - FELDON SE; LEVIN L \& LIU SK. Grave's Ophthalmopathy. Arch Ophthalmol 108: 1568-1571, 1990.

80 - UTIGER RD. The pathogenesis of autoimmune thyroid disease. N Engl J Med 325: 278-279, 1991.

81 - NUNERY WR et al. The Association of Cigarette Smoking with Clinical Subtypes of Ophthalmic Graves' Disease. Ophthalmic Plast Reconstr Surg 9: 77-82, 1993.

82 - BARTLEY GB \& GORMAN CA. Diagnostic criteria for Graves' Ophthalmopathy. Am J Ophthalmol 119: 792-795, 1995.

83 - FELDON SE. Diagnostic tests and clinical techniques in the evaluation of Graves' ophthalmopathy. In: WALL JR HOW J eds. Graves' Ophthalmopathy. Blackwell, Boston, p. $79-93,1990$.

84 - HAMMER B. Diagnosis and classification. In: HAMMER B, ed. Orbital fractures. Hogrefe \& Huber, Seattle, v. 1, p. 7-17, 1995.

85 - ROOTMAN JR. Diseases of the orbit., JB LIPPINCOTT, Philadelphia, 1988.

86 - AHL NC \& HILL JC. Horner's muscle and the lacrimal system. Arch Ophthalmol 100: 488-493, 1982.

87 - JONES LT \& MARQUIS MM. Lacrimal function. Am J Ophthalmol 73: 658-659, 1972.

88 - BECKER BB. Tricompartment model of the lacrimal pump mechanism. Ophthalmology 99: 1139-1145, 1992.

89 - ROYER J et al. Anatomie et physiologie des voies lacrymales d'excrétion. In: L'appareil lacrymal. Masson, Paris, p. 165-250, 1982.

90 - ROYER J. Pathologie et traitments du segment horizontal des voies lacrymales. In: L'appareil lacrymal. Masson, Paris, p. 253-321,1982.

91 - ROYER J. Pathologie et traitments du segment vertical des voies lacrymales. In: L'appareil lacrymal. Masson, Paris, p. 321-376, 1982.

Recebido para publicação em 03/01/97

Aprovado para publicação em 30/01/97 